\title{
OS PROCESSOS VERBAIS PRESENTES NOS ARTIGOS CIENTÍFICOS DA REVISTA GESTÃO E SECRETARIADO: UMA ANÁLISE COM BASE NA LINGUÍSTICA SISTÊMICO-FUNCIONAL
}

\section{VERBAL PROCESSES IN SCIENTIFIC ARTICLES OF THE REVISTA GESTÃO E SECRETARIADO (MANAGEMENT AND SECRETARIAD JOURNAL): AN ANALYSIS BASED ON SYSTEMIC FUNCTIONAL LINGUISTICS}

\section{Keyla Christina Almeida Portela}

Doutoranda em Linguística Aplicada e estudos da Linguagem pela Pontifícia Universidade Católica de São Paulo - PUC/SP.

Professora do curso de Bacharel em Secretariado Executivo Instituto Federal de Educação, Ciência e Tecnologia de Mato Grosso - IFMT.

E-mail: keylaportela@bol.com.br (Brasil)

\section{Karin Claudia Nin Brauer}

Doutoranda em Linguística Aplicada e estudos da Linguagem pela Pontifícia Universidade Católica de São Paulo - PUC/SP.

Professora do Instituto Federal de Educação, Ciência e Tecnologia de São Paulo - IFSP.

E-mail: karincnb@yahoo.com.br (Brasil)

\footnotetext{
Alexandre José Schumacher

Doutorando em Economia e Direção de Empresas pela Universidade La Rioja - Unioja, Espanha Professor do curso de Bacharel em Secretariado Executivo no Instituto Federal de Educação, Ciência e Tecnologia de Mato Grosso - IFMT.

E-mail: a.j.schumacher@hotmail.com (Brasil)
} 


\title{
OS PROCESSOS VERBAIS PRESENTES NOS ARTIGOS CIENTÍFICOS DA REVISTA GESTÃO E SECRETARIADO: UMA ANÁLISE COM BASE NA LINGUÍSTICA SISTÊMICO-FUNCIONAL
}

\section{RESUMO}

Este trabalho está inserido no Projeto SAL (Systemics across Languages) que possui por objetivo apoiar pesquisas linguísticas que investigam a relação entre gramática e discurso, em termos sistêmico-funcionais. O trabalho tem como objetivo analisar os processos verbais em 23 artigos científicos da revista Gestão $e$ Secretariado, publicados online, no período de 2010 a 2011. Os processos verbais, quando empregados, ratificam, esclarecem e explicam fatos ou situações, desempenhando um papel imprescindível na sustentação dos argumentos apresentados por autores frente à temática do texto. Como fundamentação teórica, será utilizada a Linguística Sistêmico-Funcional (LSF), que estuda a língua em uso em diferentes contextos, desenvolvida por Halliday (1994) e revista por Halliday e Matthiessen (2004) e outros. A pesquisa basear-seá na metafunção ideacional da Linguística Sistêmico-Funcional - que compreende a língua como atividade social, avaliando seus contextos de uso (Halliday,1994 e Halliday e Matthiessen, 2004). No que se refere aos estudos sobre gêneros científicos, a pesquisa estará fundamentada em Bhatia (1993), Swales (1990), Swales e Feak (1999), Motta-Roth (1998) e outros. O gênero artigo científico desempenha o papel de via de comunicação entre pesquisador, profissionais, professores e alunos de graduação e pós-graduação. Na análise dos dados, será observada a frequência dos processos do dizer e a sua relação com os participantes da oração (dizente e verbiagem). A metodologia utilizada será subsidiada pelo programa de Linguística de Corpus Wordsmith Tools 5.0 (Scott, 2009), mais especificamente as ferramentas wordList e concordance. Esta pesquisa pretende auxiliar o melhor entendimento de como os autores que publicam na revista Gestão $e$ Secretariado fazem uso dos processos do dizer.

Palavras-chave: Processos Verbais; Linguística Sistêmico-Funcional; Artigos Científicos.

\section{VERBAL PROCESSES IN SCIENTIFIC ARTICLES OF THE REVISTA GESTÃO E SECRETARIADO (MANAGEMENT AND SECRETARIAD JOURNAL): AN ANALYSIS BASED ON SYSTEMIC FUNCTIONAL LINGUISTICS}

\begin{abstract}
The present work makes part of Projeto SAL (Systemics across Languages) and it aims to support linguistics researches that investigate the relation between grammar and discurse, in systemic-funtional terms. This study also aims to analyze verbal processes in 23 scientific articles of the Revista de Gestão e Secretariado, online published, between 2010-2011. The verbal processes when used ratify, clarify and explain facts or situations, performimg a vital role in sustaining arguments presented by authors across the theme of the text. As a theoretical framework will be used the Systemic Functional Linguistics (SFL) which studies language in use in different contexts, it was developed by Mak Halliday $(1985,1994)$ and reviewed by Halliday and Matthiessen (2004) and others. The research will be based on the ideational metafunction of Systemic Functional Linguistics - which understands the language as a social activity, assessing its contexts of use (Halliday, 1994 and Halliday \& Matthiessen, 2004). The survey will be also based on Bhatia (1993), Swales (1989, 1990), Swales \& Feak (1999), Motta-Roth $(1995,2006)$ and others in the part of the study that refers to scientific genres. The scientific article genre develops the function of a communication between researcher, professionals, academics and undergraduate and postgraduate students. The frequency of the processes of say will be observed in the analyze of the data and its relation with the participants of the sentence (uttering and verbiage). The methodology will be subsidized by the Corpus Linguistics program Wordsmith Tools 5.0 (Scott, 2009), more specifically the wordlist and concordance tools. This research develop a better understanding of how the authors who publish in the Revista Gestão e Secretariado make use of the processes of say.
\end{abstract}

Keywords: Verbal Processes; Systemic Functional Linguistics; Scientific Articles.

Revista de Gestão e Secretariado - GeSec, São Paulo, v. 5, n. 2, p 97-116, mai./ago. 2014. 


\section{INTRODUÇÃO}

A preocupação em estudar a escrita acadêmica e o aumento significativo de publicações de artigos científicos no Brasil e no mundo, Motta-Roth (1998), fazem com que novos estudos e pesquisas sejam realizados nesta área.

Isso mostra a importância que o gênero artigo científico assumiu dentro da sua esfera de circulação, sendo considerado um dos principais meios de divulgação da ciência entre os pesquisadores.

Buscando identificar as características da escrita acadêmica, optou-se por estudar os artigos científicos de Secretariado Executivo, tendo como objetivo analisar os processos verbais de 23 artigos científicos da revista Gestão e Secretariado (Gesec), publicados online. Os processos verbais, quando empregados, ratificam, esclarecem e explicam fatos ou situações, desempenhando um papel imprescindível na sustentação dos argumentos apresentados por autores frente à temática do texto. Além disso, também se buscou a análise dos tipos de Dizentes e as Verbiagens.

A Linguística Sistêmico-Funcional, especificamente a metafunção ideacional, será utilizada como aporte teórico, pois ela compreende a língua como atividade social, avaliando seus contextos de uso (Halliday,1994 e Halliday \& Matthiessen, 2004). No que se refere aos estudos sobre gêneros científicos, a pesquisa estará fundamentada em Bhatia (1993), Swales (1990), Swales e Feak (1999), Motta-Roth (1995) e outros.

Esta pesquisa está inserida no Projeto SAL (Systemics across Languages), que possui como objetivo apoiar pesquisas linguísticas que investigam a relação entre gramática e discurso em termos sistêmico-funcionais.

Como abordagem metodológica, optou-se pela Linguística de Corpus, a qual proporciona ferramentas de análises, pautadas em coleta e análise de dados linguísticos reais, (Berber Sardinha, 2000) o que permite estudar uma grande quantidade de textos. A ferramenta computacional Wordsmith Tools 5.0 (Scott, 2009) da Linguística de Corpus foi utilizada para alcançar o objetivo da pesquisa.

\section{A GRAMÁTICA SISTÊMICO- FUNCIONAL}

A gramática tradicional tem por objetivo manter regras sintáticas, muitas vezes dissociadas de suas considerações sobre o significado ou das propostas sociais; já a gramática de Halliday,

Revista de Gestão e Secretariado - GeSec, São Paulo, v. 5, n. 2, p 97-116, mai./ago. 2014. 
chamada de gramática sistêmico-funcional tem como base a Semântica e não a Sintaxe. Assim, é possível verificar os papéis das variações linguísticas no texto, no que diz respeito à sua função na construção do significado, tendo como ponto de partida sua base funcional.

A gramática sistêmico-funcional pesquisa tanto a linguagem escrita como a falada, com a intenção de diferenciá-las. Esta gramática possibilita uma profunda análise textual, observando a forma como a configuração linguística é constituída em um gênero específico, levando em consideração o contexto no qual o texto está inserido.

Os gêneros, na gramática sistêmico-funcional, demonstram as interações, por meio da linguagem verbal, que ocorrem entre os indivíduos, com o intuito de analisar como a configuração linguística acontece em um gênero em particular.

Martin (1992) pesquisou a existência de gêneros, buscando as características originais dadas por Malinowski (1974) entre contexto de situação e de cultura. Esta diferenciação entre gêneros de Malinowski também é usada por Halliday e Hasan (1989).

Martin (1985) observou que um texto remete a um conjunto de escolhas linguísticas que se referem ao campo, relações e modo. De acordo com o pesquisador, esses elementos são a condição do contexto de situação. Para ele um texto é como uma instanciação de um gênero particular, em que a escolha do gênero seria uma condição do contexto de cultura. E sob esta visão, diferencia contexto de situação e contexto de cultura, mostrando que em um texto podem ser verificadas escolhas linguísticas que remetem ao campo, relações e modo, elementos condicionantes do contexto de situação. E um texto instancia um gênero e o texto desenvolvimento condiciona o contexto de cultura, sendo um sistema de gêneros.

De acordo com Motta-Roth e Herbele (2005:15), em relação ao contexto de situação e contexto de cultura, observa-se que um conjunto compartilhado de contextos de situação constrói um dado contexto de cultura, sistema de experiências com significados compartilhados. Desse modo, o sujeito é formado pela soma das próprias interações e pelos códigos semióticos em funcionamento nas comunidades em que participa.

Assim, o contexto de cultura seria o que resulta da padronização do discurso no que se refere a atos retóricos ou de fala, sendo que eles ocorrem por meio da linguagem, na qual as suas características retóricas acontecem em circunstâncias específicas.

As metafunções hallydianas conhecidas como ideacional, textual, interpessoais manifestamse em um sistema linguístico, funcionando de maneira subjacente a todos os empregos da língua: ideacional (entender o meio), interpessoal (interagir com os outros) e textual (organização do texto). 
que falamos, por exemplo, expressões do próprio ser. Conforme Neves (1997:12), é por meio desta função que o falante e o ouvinte organizam e incorporam na língua sua experiência dos fenômenos do mundo, o que inclui sua experiência dos fenômenos do mundo interno da própria consciência.

A Metafunção Ideacional é constituída de dois modos: o experiencial e o lógico. Segundo Martin, Matthiessen e Painter, (1997:100) o modo lógico possibilita os recursos formar diferentes tipos de complexos - como, por exemplo, oracionais, e desenvolve sua função com o modo experiencial na ordenação de grupos. Esse modo está na oração e é expresso pelo sistema de transitividade, que equivale a um sistema de descrição de toda a oração, a qual é constituída de processos, participantes e eventuais circunstâncias.

Os processos são os elementos centrais da configuração, indicando a experiência se desdobrando através do tempo. Participantes são as entidades envolvidas, ou seja, pessoas ou coisas. Circunstâncias adicionam significados à oração pela descrição do contexto do qual o processo se realiza (Fuzer e Cabral, 2010:30).

Na Figura 1, visualizam-se os seis tipos de processos, organizados em torno de diferentes campos semânticos da experiência humana: material, existencial, relacional, verbal e mental (Halliday e Mathiessen, 2004:167- 280).

Figura 1 - Tipos de Processos

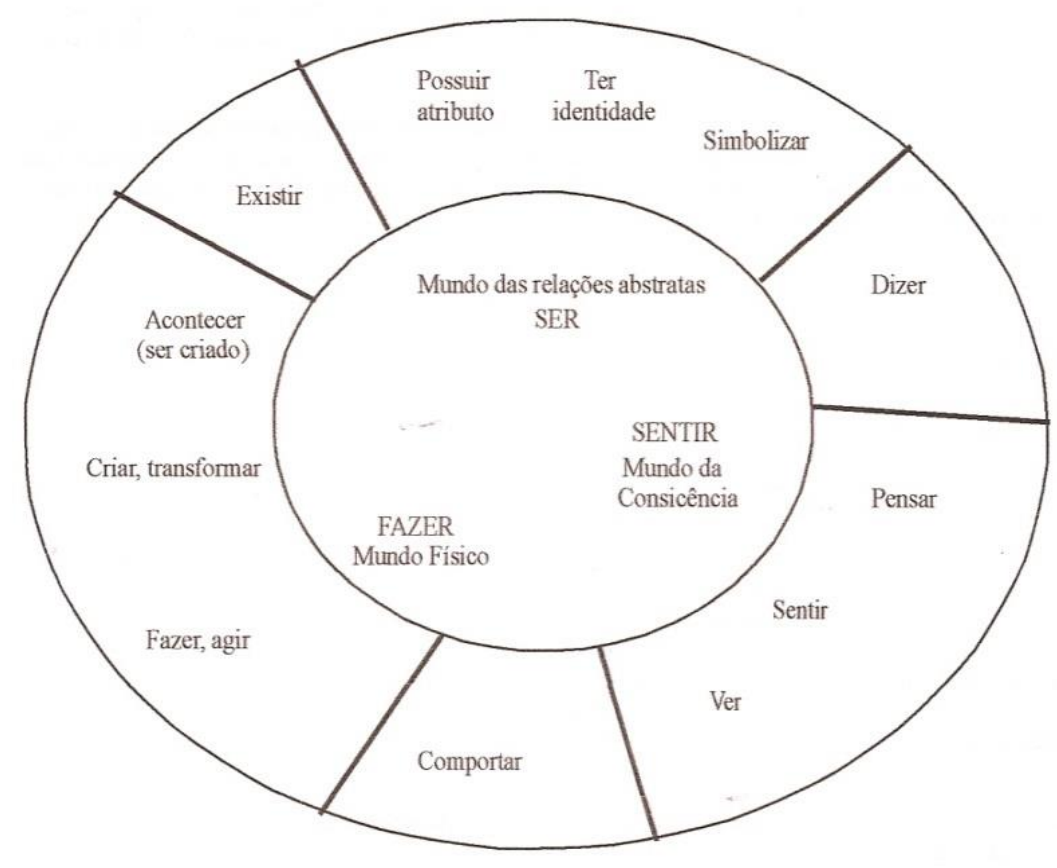

Fonte: Traduzida de Halliday e Mathiessen, 2004:172)

Revista de Gestão e Secretariado - GeSec, São Paulo, v. 5, n. 2, p 97-116, mai./ago. 2014. 
A organização dos diferentes tipos de processo em uma figura circular visa demonstrar que há certa continuidade nos significados das ações e experiências humanas e no significado dos processos. Alguns processos são classificados como "principais", como material, mental e relacional, e os considerados de "fronteira", qualificados como comportamental, verbal e existencial. Os processos materiais são aqueles que representam ações no campo semântico do fazer, criar, transformar e acontecer, implicando trabalho ou empenho de energia. Além disso, eles são significados associados ao mundo físico e à experiência no mundo externo. Os mentais simbolizam as experiências humanas internas, o pensar e o querer. Os relacionais são responsáveis pela realização linguística das relações abstratas, relacionadas à classificação e determinação de coisas ou pessoas. Os verbais são responsáveis pelas ações de fala, pela realização linguística das relações simbólicas no discurso. Os comportamentais estão relacionados às questões típicas do comportamento humano, como fenômenos fisiológicos ou manifestações físicas relacionadas à consciência humana. Os existenciais indicam ações que existem ou acontecem, normalmente associadas a fenômenos socialmente reconhecidos. Cada um desses tipos de processo é acompanhado por participantes diferentes, grupos nominais que realizam diferentes significados, além das circunstâncias, grupos adverbiais e preposicionais.

\subsection{O GÊNERO ARTIGO CIENTÍFICO}

O gênero textual tem sido particularmente útil para compreender as práticas discursivas acadêmicas e profissionais, em que enunciados altamente individuais e estratégicos são produzidos em formas bastante distintivas e reconhecíveis.

Para Bazerman (2009:60), o surgimento de um gênero está ligado intricadamente às mudanças nas relações e nos papéis profissionais, à ideologia, à epistemologia e outros.

O autor (2009) ainda afirma que os gêneros não podem ser definidos apenas por um conjunto de traços textuais, pois não se pode ignorar a função dos indivíduos no uso e na construção de sentidos, as diferentes formas de percepção e compreensão, nem a criatividade da comunicação humana, na busca pela satisfação de novas necessidades decorrentes de novas circunstâncias, além das novas formas de compreensão do gênero no decorrer do tempo.

O gênero, uma vez estabelecido, torna-se um ambiente estruturado para a escrita e para a leitura, que, por sua vez, exerce influência sobre os outros aspectos do trabalho profissional. Exemplo disso é o gênero artigo científico, que é usado por pesquisadores para divulgação de pesquisas.

Revista de Gestão e Secretariado - GeSec, São Paulo, v. 5, n. 2, p 97-116, mai./ago. 2014. 
O artigo científico insere-se nos gêneros acadêmicos, é considerado como uma maneira de participar, agir e construir o conhecimento científico sócio-retórico, além de se inserir no domínio discursivo da ciência do qual mostra as ações sociais de produção do conhecimento.

Esse tipo de gênero resulta em um relato sobre pesquisas desenvolvidas por cientistas e tem como objetivo divulgar os resultados obtidos no meio científico, trazendo novas propostas, teorias e exercendo a função de divulgador da pesquisa científica, além de utilizar aspectos linguísticos específicos com uma linguagem objetiva, usos de termos técnicos e algumas vezes fazendo o ocultamento do produtor do texto.

Swales (1990) afirma que o artigo científico é um gênero da comunidade acadêmica e disciplinar, além de ser considerado um dos principais veículos de socialização do conhecimento e de exercer a função de inserir novos pesquisadores nas comunidades científicas e, desse modo, também está relacionado a descobertas científicas.

Esse autor (1990) ainda conceitua o artigo científico (Research Article) como um texto escrito (embora possa conter elementos da linguagem não verbal) com o uso limitado de palavras que se reportam a algumas pesquisas por um ou mais autores. Ele também apresenta três conceitoschaves para definir o que é gênero, isto é, como um evento comunicativo, um propósito comunicativo, e uma comunidade discursiva. O evento comunicativo é qualquer evento "onde a linguagem (e/ou para-linguagem) desempenha um papel significativo e indispensável” (Swales, 1990:45). O propósito comunicativo refere-se aos "gêneros como veículos de comunicação para a realização de objetivos" (Swales, 1990:46). Além disso, é a existência de um ou mais propósitos comunicativos que torna um conjunto qualquer de eventos comunicativos num gênero. $O(s)$ propósito(s) comunicativo(s) é (são) a(s) principal(is) característica(s) do gênero, mesmo que esse(s) possa(m) ser algumas vezes de difícil identificação, implicando dificuldades conceituais. O autor resume que o gênero pode ser entendido como um modo de interação de uma dada comunidade discursiva, que possui propósito(s) comunicativo(s) específico(s), os quais determinam os componentes da estrutura esquemática do discurso, restringindo, portanto, as escolhas de conteúdo e estilo.

Motta-Roth (1995) diz que os gêneros discursivos são os mais utilizados por pesquisadores

na leitura e na publicação científicas. É neles que estão os capítulos de livros e artigos de revistas acadêmicas. Nesse contexto, podemos considerar o artigo científico um dos gêneros mais utilizados no ambiente científico como forma de acesso e de produção de conhecimento científico.

Revista de Gestão e Secretariado - GeSec, São Paulo, v. 5, n. 2, p 97-116, mai./ago. 2014. 
A autora (1995:65) ainda traz o gênero "artigo científico como sendo uma via de comunicação entre pesquisador, profissionais, professores e alunos de graduação e pós-graduação”. Portanto, convém que os autores saibam articular a linguagem (formato e vocabulário técnico) para imprimir as convenções do registro da área em que atuam e escrever pesquisas seguindo os hábitos da área, apresentar o problema, apresentar dados, avaliar os resultados, argumentar e tirar conclusões, fazendo com que a informação circule e tenha impacto na área do conhecimento.

Kanoksilapatham (2005) afirmam que o artigo científico é fruto da atividade de pesquisa da comunidade de onde foi gerado, e que apresenta como características a alusão a outras pesquisas ou autores que compartilham ou não do mesmo assunto tratado, uma apresentação de objetivos posteriores à identificação de um problema apontado, a citação de outras pesquisas que possam corroborar na apresentação e a generalização dos resultados obtidos.

Nesse sentido, o artigo pode ser considerado como meio responsável pela divulgação de um estudo, reunindo etapas que se estendem desde a contextualização de uma pesquisa até a conclusão do estudo realizado.

A seguir, discutiremos as questões metodológicas que orientarão este artigo.

\section{METODOLOGIA}

O corpus desta pesquisa é constituído de 23 artigos científicos, online, da área de Secretariado Executivo da Revista Gestão e Secretariado, analisados todos do período de 2010 a 2011. Esta revista publica estudos de caráter teórico e/ou aplicado, oriundos da área de Gestão e Secretariado Executivo.

Para a organização e tratamento dos dados, com o objetivo de observar a frequência dos processos verbais e verificar os tipos de Dizentes e as Verbiagens os artigos científicos foram salvos em $t x t$, e posteriormente, utilizou-se do instrumento computacional da Linguística de Corpus, Wordsmith Tools 5.0 (Scott, 2009), mais especificamente os recursos do Wordlist e Concordance.

O instrumento de análise oferecido pela ferramenta Wordlist possibilita a criação de listas de palavras que abrangem todas as palavras do corpus e identifica a frequência de ocorrência em valores absolutos - o número total de palavras (token), frequência relativa - o número de palavras diferentes (types), bem como a proporção entre dois números, fornecida em porcentagem (ratio).

Com a ferramenta concordance é possível analisar o uso da palavra em seu contexto; em uma análise das colocações (palavras próximas à palavra analisada) e também observar as

Revista de Gestão e Secretariado - GeSec, São Paulo, v. 5, n. 2, p 97-116, mai./ago. 2014. 
estruturas gramaticais nas quais as palavras são utilizadas e identificar padrões gramaticais.

\section{ANÁLISE DOS DADOS}

Visando a atingir os objetivos desta pesquisa, primeiramente, elaborou-se uma lista de palavras gerada pelo Wordsmith Tools, do qual foram elencados os verbos mais recorrentes e, a partir das concordâncias, foram levantadas as formas verbais mais ocorrentes, os tipos de Dizentes e Verbiagens.

Para a análise do corpus coletado, foi realizado um levantamento de dados quantitativos extraindo os dados gerais do corpus conforme Tabela 1.

Tabela 1 - Informação estatística do corpus de pesquisa

\begin{tabular}{|l|c|}
\hline & REVISTA GEST $\tilde{\boldsymbol{O}} \boldsymbol{O}$ E SECRETARIADO \\
\hline Tamanho do corpus (bits) & 852,786 \\
\hline Número de palavras & 129,431 \\
\hline Número de palavras diferentes & 10,839 \\
\hline Número de textos & 23 \\
\hline
\end{tabular}

Fonte: Elaborado pelos autores

Posteriormente, utilizando a ferramenta Wordlist do Wordsmith Tools 5.0 foi possível elaborar uma tabela com a frequência de cada verbo do dizer do corpus da revista estudada.

Tabela 2 - Frequência dos processos verbais mais recorrentes

\begin{tabular}{|c|c|c|}
\hline POSIÇÃO & VERBO & FREQ \\
\hline 1 & Dizer & 67 \\
\hline 2 & Estabelecer & 33 \\
\hline 3 & Ressaltar & 28 \\
\hline 4 & Definir & 27 \\
\hline 5 & Apontar & 24 \\
\hline 6 & Demonstrar & 24 \\
\hline 7 & Afirmar & 23 \\
\hline 8 & Falar & 23 \\
\hline 9 & Descrever & 21 \\
\hline 10 & Demandar & 19 \\
\hline
\end{tabular}

Revista de Gestão e Secretariado - GeSec, São Paulo, v. 5, n. 2, p 97-116, mai./ago. 2014. 
Os processos verbais presentes nos artigos científicos da revista gestão e secretariado: uma análise com base na linguística sistêmico-funcional

\begin{tabular}{|c|c|c|}
\hline 11 & Destacar & 17 \\
\hline 12 & Determinar & 16 \\
\hline 13 & Mencionar & 16 \\
\hline 14 & Perguntar & 16 \\
\hline 15 & Mostrar & 15 \\
\hline 16 & Participar & 15 \\
\hline 17 & Propor & 15 \\
\hline 18 & Responder & 15 \\
\hline 19 & Discutir & 13 \\
\hline 20 & Enfatizar & 8 \\
\hline 21 & Relatar & 7 \\
\hline 22 & Informar & 6 \\
\hline 23 & Sugerir & 6 \\
\hline 24 & Pedir & 4 \\
\hline 25 & Questionar & 4 \\
\hline 26 & Retomar & 4 \\
\hline 27 & Concordar & 2 \\
\hline 28 & Defender & 2 \\
\hline 29 & Postular & 1 \\
\hline \multirow[t]{2}{*}{30} & Testemunhar & 1 \\
\hline & Total & 472 \\
\hline
\end{tabular}

Fonte: Elaborado pelos autores

Na Tabela 2, foi possível perceber que o processo verbal Dizer foi o mais frequente em todo o corpus.

Para analisar as formas verbais mais frequentes no corpus, os Dizentes e Verbiagens foram utilizados os 10 primeiros processos verbais mais recorrentes.

Utilizando a ferramenta Concordance do software Wordsmith Tools 5.0 (Scott, 2009) foi possível criar algumas categorias de uso de alguns verbos, buscando verificar se o processo utilizado nos artigos científicos realmente desempenham a função de processo verbal.

O primeiro verbo a ser analisado foi o verbo dizer conforme Tabela 3.

Revista de Gestão e Secretariado - GeSec, São Paulo, v. 5, n. 2, p 97-116, mai./ago. 2014. 
Tabela 3 - Análise do Verbo "Dizer"

\begin{tabular}{|l|c|c|c|c|}
\hline \multicolumn{1}{|c|}{ DIZER } & & & & \\
\hline \multicolumn{1}{|c|}{ categorias } & material & verbal & relacional & mental \\
\hline diz que & & 4 & 1 & \\
\hline diz como & & 1 & & \\
\hline diz respeito a & 1 & 2 & 22 & \\
\hline podemos dizer & & 4 & & \\
\hline dizer que & & 4 & & \\
\hline quer dizer & & & 2 & \\
\hline se diz & & & 1 \\
\hline
\end{tabular}

Conforme é possível observar, na Tabela 3, o verbo dizer não aparece apenas como processo verbal, mas também na forma de processos materiais, relacionais e mentais.

A categoria "diz respeito $a$ " teve uma maior ocorrência como processo relacional. Vejamos alguns exemplos:

1. "Essa quebra de paradigma é consequência das mudanças culturais da sociedade no que diz respeito à questão de identidade" (Barros, Izequiel \& Silva, 2011).

2. "Identificar um quadro de cinco grupos com necessidades similares ao mesmo tempo no que diz respeito à amplitude do conhecimento em língua estrangeira" (Sanctis \& Abib, 2010).

Nos exemplos 1 e 2 é possível observar que a utilização do verbo dizer não tem função de processo verbal, mas sim, de processo relacional, pois os verbos estão sendo utilizados na ideia de "referir, significar, indicar, resultar".

Nota-se que o processo dizer também pode ter o sentido de acreditar, sentir, sendo assim, um processo mental, conforme o exemplo abaixo:

3. Koener se diz aliviado - e demonstra isso em seu texto - em fazer tal afirmação por estar seguro que [...] (Zanon, 2010).

Revista de Gestão e Secretariado - GeSec, São Paulo, v. 5, n. 2, p 97-116, mai./ago. 2014. 
Tabela 4 - Análise do Verbo "Estabelecer"

\begin{tabular}{|l|c|c|l|}
\hline \multicolumn{1}{|c|}{ ESTABELECER } & & & \\
\hline \multicolumn{1}{|c|}{ categorias } & material & verbal & existencial \\
\hline se estabelecer & 4 & & \\
\hline e estabelece & 2 & 4 & \\
\hline estabelecer & 1 & 4 & \\
\hline estabelecendo-se & 1 & & \\
\hline estabelece-se & 1 & 1 & \\
\hline
\end{tabular}

Fonte: Elaborado pelos autores

Conforme Tabela 4, é possível notar que o processo estabelecer, em alguns casos, pode ser um processo material. No exemplo 4, podemos ver que o processo não é verbal, mas sim, material, pois o processo estabelecer está com o sentido de criar, planejar.

No exemplo 5, ocorre a mesma situação, pois o processo estabelecer está com o sentido de expandir, crescer, sendo assim um processo material e não verbal. Já no exemplo 6, o processo estabelecer tem o sentido de haver, tornando o processo estabelecer em existencial.

4. O ideal é estabelecer desde o início um sistema de controle estatístico classificação, acondicionamento e uso... (Dudziak, 2010).

5. Apesar do número muito grande de empresas de países centrais estabelecendose em países semiperiféricos em busca da melhor relação custo/benefício... (Martins, Terra \& Maccari, 2010).

6. Estabelece-se a necessidade de realizar, mais do que a simples organização de arquivos, a gestão de documentos e arquivos. Para mim parece que é material, pois tem um sentido de criar (Vitalis, Geötzke \& Andriolo, 2011).

Tabela 5 - Análise do Verbo "Apontar"

\begin{tabular}{|l|c|c|c|}
\hline \multicolumn{1}{|c|}{ APONTAR } & & & \\
\hline categorias & material & verbal & relacional \\
\hline apontado que & & 1 & \\
\hline apontam para & 1 & 4 & \\
\hline apontam as & 1 & 4 & \\
\hline aponta como & & 5 & \\
\hline
\end{tabular}

Fonte: Elaborado pelos autores 
O processo apontar foi o mais empregado como processo verbal e não houve nenhum caso de processo relacional, conforme Tabela 5. No entanto, ocorrem alguns casos em que funciona como processos materiais, com o sentido de mostrar, exibir. Vejamos os exemplos 6 e 7.

7. As competências atuais do secretário executivo que se relacionam com a gestão, visando apontar as possibilidades de o secretário assumir cargos de gestão (Durante et. al., 2011).

8. E conclui que a maioria dos materiais aponta para uma identidade duvidosa do profissional de secretariado (Sartoti, 2011).

Tabela 6 - Análise do Verbo "Ressaltar"

\begin{tabular}{|l|l|c|l|}
\hline \multicolumn{1}{|c|}{ RESSALTAR } & & & \\
\hline \multicolumn{1}{|c|}{ categorias } & material & verbal & relacional \\
\hline é importante ressaltar & & 13 & \\
\hline ressalta que & & 11 & \\
\hline ressalta que o & & 9 & \\
\hline ressalta-se que & & 6 & \\
\hline
\end{tabular}

Fonte: Elaborado pelos autores

Já o processo ressaltar aparece apenas como processo verbal. Exemplos:

9. Finalmente, cabe ressaltar que o processo de globalização parece não estar em desaceleração, as mudanças são diárias (Silva \& Polaczek, 2010).

10. Vale ressaltar que o retorno ao mundo do trabalho é sempre mais complicado para quem dele permanece afastado durante um espaço de tempo e trabalho em curtas jornadas são mais difíceis de encontrar [...] (Whitaker \& Cavalcanti, 2010).

Para classificar os Dizentes e a ocorrência de Verbiagens nesta pesquisa, também se fez uso da ferramenta Concordance do qual se obtiveram quatro categorias de Dizentes: elíptico, indeterminado, lexicalizado e pronominalizado, no entanto, não são todas essas categorias que ocorrem nos processos verbais.

Revista de Gestão e Secretariado - GeSec, São Paulo, v. 5, n. 2, p 97-116, mai./ago. 2014. 
O Dizente enquanto elíptico é determinado pela desinência verbal e não aparece explícito na oração. Dá-se por isso o nome de dizente implícito. Nos exemplos abaixo, observa-se o pronome nós implícito na conjugação verbal em alguns processos do dizer.

Exemplo 1: No transcorrer desta pesquisa, estabelecemos o percurso historiográfico dos Manuais de Correspondências Comerciais (Zanon, 2010).

Exemplo 2: Ressaltamos que todas as características citadas nessa questão são importantíssimas para o bom funcionamento do corpo e da mente (Ortega e Araújo, 2011).

Exemplo 3: Para um melhor entendimento, posteriormente descreveremos um subcapítulo a respeito de algumas doenças que estão ligadas ao excesso de estresse (Ortega e Araujo, 2011).

Os Dizentes enquanto indeterminados são aqueles que realizam o processo, mas não é permitido ao leitor identificá-los. Ele apresenta sua construção com um processo na $3^{\text {a }}$ pessoa do singular, acompanhado do pronome se ou com processos em terceira pessoa sem referência ao agente. Segue abaixo alguns exemplos com os processos verbais analisados:

Exemplo 4: Estabelece-se a necessidade de realizar, mais do que a simples organização de arquivos, a gestão de documentos e arquivos (Dudziak, 2010).

Exemplo 5: Ressalta-se que paralelamente a toda evolução do papel do profissional de secretariado houve mudanças na área da Educação (Almeida, Rogel \& Shimoura, 2010).

Exemplo 6: A primeira fase, que se deu entre as décadas de 60 e 70, quando os professores de língua estrangeira não tinham muito conhecimento sobre o ensino da língua para estudantes em áreas específicas, definiu-se necessidade de aprendizado como o desenvolvimento de gramática e vocabulário em textos da área científica (Sanctis \& Abib, 2010).

Os Dizentes classificados como lexicalizados têm como base o próprio núcleo - um substantivo. Nos exemplos a seguir, será possível observar como os sintagmas nominais Revista de Gestão e Secretariado - GeSec, São Paulo, v. 5, n. 2, p 97-116, mai./ago. 2014. 
ocorreram em alguns dos processos do dizer.

Exemplo 8: Bakhtin (2000, p. 283) diz que é próprio dos gêneros desse universo a forma padronizada e a tentativa de desfavorecer a individualidade (Nascimento, 2010).

Exemplo 9: CONARQ (2006, p.21) ressalta que o processo de implantação deve envolver "a execução e o acompanhamento de ações e projetos, efetuados simultaneamente (Lourenço \& Cantarotti, 2010).

Exemplo10: Solon Buck definiu "Arquivo" como: “[...] o conjunto de documentos oficialmente produzidos e recebidos por um governo, organização ou firma, no decorrer de suas atividades, arquivados e conservados por si e seus sucessores para efeitos futuros" (Vitalis, Geotzke \& Andriolo, 2011).

Exemplo 11: St John (1998, p. 122-4) aponta três tendências para se determinar as necessidades dos estudantes no ensino de uma língua estrangeira (Sanctis \& Abib, 2010).

Exemplo 13: Carvalho e Grisson (2002, p. 453) afirmam que este profissional utiliza sua sensibilidade para Gestão Educacional (Mascarenhas, Sepulveda \& D’Assumpção, 2011).

Exemplo 14: Alves (2004, p. 53) fala que cliente externo "é aquele que sofre o impacto dos [...] serviços que oferecemos." e que cliente interno "são todas as pessoas que trabalham na organização e que influenciam diretamente [...] na prestação de serviços" (Decker, 2010).

Exemplo 15: Libâneo (2008) descreve o papel da Organização Educacional como sendo "A atuação da escola consiste na preparação intelectual e moral dos alunos para assumir sua posição na sociedade. O compromisso da escola é com a cultura e os problemas sociais à sociedade (Gianini \& Gerardin Junior, 2010). 
Os exemplos 13 a 15 fazem referência à voz de outros autores para confirmar ou dar mais credibilidade àquilo que está sendo dito. Esse recurso é muito utilizado em artigos científicos. Além disso, nos referidos exemplos, ainda é possível perceber o uso do sobrenome dos autores referenciados, recurso também utilizado em redações científicas.

Os Dizentes, classificados como pronominalizados são aqueles representados por um pronome explícito na construção da oração. Nos exemplos a seguir, os pronomes nos e ele aparecem representando os autores.

Exemplo 16: Quando alguém nos diz que está estressado já imaginamos que esse indivíduo está esgotado física e emocionalmente (Ortega e Araujo, 2011).

Exemplo 17: Sendo assim, a partir da conclusão de Ribeiro (1994, p. 25), onde ele diz que "[...] antes, durante e depois da aplicação e implantação do programa 5S (Decker, 2010).

Com relação à verbiagem foram encontradas duas categorias: a verbiagem de conteúdo e a de nome do dizer. As de conteúdo estão relacionadas ao assunto tratado na interação. As de nome são associadas ao uso de expressões como "dizer uma mentira" ou "contar uma história". No entanto, a distinção entre os dois nem sempre é clara, devido ao contexto em que cada um dos elementos aparece. De acordo com Halliday e Mathiessen (2004), as verbiagens são formadas por classes de coisas ou grupos nominais. Abaixo seguem alguns exemplos.

Verbiagem de conteúdo: descrição da situação

Dizemos confusão já que se trata de atividades diferentes, tomadas sempre como única (Zanon, 2010).

Verbiagem de nome do dizer: ato de fala

Formas de dizer o discurso são aprendidas e estão de acordo com as tradições culturais de uma sociedade (Leila e Macedo, 2011). 


\section{CONCLUSÃO}

Esse trabalho buscou analisar os processos verbais, os tipos de Dizentes e as Verbiagens nos artigos científicos de Secretariado Executivo da Revista Gestão e Secretariado, publicados online.

A partir deste estudo, constatou-se que, entre os dez processos mais recorrentes, obteve destaque, em primeiro lugar, o processo dizer. Tendo como função semântica mais atuante o processo relacional, devido à alta frequência da forma verbal diz respeito a, que foi percebida em 22 situações com o sentido de significar. Nos demais processos, observou-se uma ocorrência maior de processos verbais. No que tange aos dizentes, foi possível encontrar quatro categorias: pronominalizado, lexicalizado, indeterminado e elíptico. As verbiagens apresentaram duas categorias: de conteúdo e de assunto.

É possível concluir, desta forma, que o predomínio maior de processos se mantém nos relacionais, seguidos dos verbais, porém observou-se que em alguns verbos como no dizer foi o relacional e nos demais foi verbal.

Nesse modo, este estudo foi importante e trouxe uma contribuição para área secretarial, pois foi possível verificar que muitos pesquisadores que publicaram no periódico ora analisado, fazem uso dos processos verbais com o sentido de outros processos. Além disso, esta pesquisa permite uma sugestão de um futuro estudo, buscando saber qual a razão pela qual os profissionais que publicaram nesta revista se utilizam de processos verbais com outro sentido.

\section{REFERÊNCIAS}

Almeida, W. A; Rogel, G. T \& Shimoura, A. S. (2010). Mudanças de paradigmas na gestão do profissional de secretariado. Revista Gestão e Secretariado, vol. 1, n.1, 46-68.

Barros, C. M. P; Izequiel, D. S. A. \& Silva, J. S. (2011). Os desafios enfrentados pelo profissional de secretariado executivo do gênero masculino nas organizações contemporâneas. Revista Gestão e Secretariado, vol. 2, n. 1, 158-176.

Revista de Gestão e Secretariado - GeSec, São Paulo, v. 5, n. 2, p 97-116, mai./ago. 2014. 
Bhatia, V. K. (1993). Analysing genre: language use in professional settings. Longman.

Bazerman, C. (2009). Escrita, gênero e interação social. São Paulo, Cortez.

Berber Sardinha, Tony. (2000). Linguística de corpus: histórico e problemática. DELTA (Documentação de Estudos em Linguística Teórica e Aplicada), São Paulo, EDUC, Vol. 16, n. 2: $323-367$.

Bhatia, V.(1993). Analysing Genre: language use in professional settings. London: Longman.

Bonzanini, S. H. S. (2010). O profissional de secretariado executivo nas relações internacionais. Revista Gestão e Secretariado, vol. 1, n.2, 142-161.

Carter, R. P. L. (2011). O bom desempenho da secretária executiva bilíngue na redação da correspondência comercial. Revista Gestão e Secretariado, vol. 2, n.1, 77-100.

Decker, D. O. (2010). A secretária como agente de qualidade. Revista Gestão e Secretariado, vol.1, n.2, 5-31.

Dudziak, E. A. (2010). Arquivos e documentos empresariais: a organização cotidiana à gestão eficiente. Revista Gestão e Secretariado, vol.1, n.1, 90-110.

Durante, D. G. et. al. (2011). Atuação e ascensão profissional a partir da formação em secretariado executivo: levantamento com egresso da UPF/RS. Revista Gestão e Secretariado, vol.2, n. 2, $170-193$

Halliday, M. A. K. (1994). An introduction to functional grammar. London: Edward Arnold.

Halliday, M. A. K.; Matthiessen, C. M. I. M. (2004). An Introducion to Functional Grammar (third edition).. London: Arnold.

Halliday, M.A.K. e Hasan, R. (1989) Cohesion in English. London: Longman.

Fonseca, E. C.; Parra, P. S.; Azevedo, M. S. \& Lopes, P. C (2010). A secretária executiva no processo de governança corporativa na empresa familiar. Revista Gestão e Secretariado, vol. 1, n.1, 1-24.

Fuzer, C. \& Cabral, S. R. S. (2010). Introdução à gramática sistêmico-funcional em língua portuguesa. Santa Maria/RS; NELP, DLV, UFSM.

Gianini, V. C. \& Gerardin Junior, U. (2010). Gestão educacional: a atuação do profissional secretário nas organizações educacionais. Revista Gestão e Secretariado, vol. 1, n. 2, 30-50.

Revista de Gestão e Secretariado - GeSec, São Paulo, v. 5, n. 2, p 97-116, mai./ago. 2014. 
Leila, B.; Macedo, C. M. (2011). Processos verbais em artigos acadêmicos: padrões de realização da mensagem. In: Textos e linguagem acadêmica: explorações sistêmico funcionais em espanhol e português. Campinas, São Paulo: Mercado de Letras.

Lourenço, F. M. A. \& Cantarotti, A. (2010). A prática do conhecimento do profissional de secretariado executivo na organização de arquivos: um estudo de caso. Revista Gestão e Secretariado, vol. 1, n.1, 111-138.

Kanoksilapatham, B. (2005). Rhetorical structure of biochemistry research articles. English for Specifics Purposes, vol. 24, 269-292.

Lima-Lopes, R. E. (2001) Estudos de transitividade em língua portuguesa: o perfil do gênero cartas de venda. Dissertação de Mestrado. LAEL - PUCSP.

Malinowki. B (1974). Magic, Science and religion and other essays. London Souvenir Press.

Martin, J. R. (1992). English text: System and Structure. Amsterdam: John Benjamins Publishing Co.

Martin, J. R.; Matthiessen, C. M. I. M. \& Painter, C. (1997). Working with functional grammar. London: Arnold.

Martins, C. B.; Genghini, L. A.; Vicente, I. \& Terra, P. M. M. (2010). Prováveis influências do primeiro ano do curso de Secretariado Executivo Bilíngue no cotidiano dos estudantes. Revista Gestão e Secretariado, vol. 1, n. 2, 51-76.

Martins, E. B. \& Kundman, M. S. (2010). As representações gramaticais de alunos de Secretariado Executivo. Revista Gestão e Secretariado, vol. 1, n.1, 164-185.

Martins, C. B.; Terra, P. M.; Maccari, E. A. \&Vicente, I. (2010). A formação do profissional em Secretariado Executivo no mercado de trabalho globalizado. Revista Gestão e Secretariado, vol. 1, n.1, 69-89.

Mascarenhas, M. H. S.; Sepulveda, F. A. M. \& D’Assumpção, E. S. (2011). Sistema de gestão integrado: a atuação do secretário executivo. Revista Gestão e Secretariado, vol. 2, n. 1, 177-192.

Motta-Roth, D. (1998). Escritura, gêneros acadêmicos e construção do conhecimento. In: Letras, vol. 17, UFSM, Santa Maria: Palloti, 93-110.

Motta-Roth, D; Herbele, A.(2005). A importância do conceito de gêneros discursivos no ensino de redação acadêmica. Intercâmbio, PUC-SP, vol. 8, 119-128.

Revista de Gestão e Secretariado - GeSec, São Paulo, v. 5, n. 2, p 97-116, mai./ago. 2014. 
Nascimento, E. P. (2010). Gêneros do universo oficial/empresarial: para além dos manuais de redação. Revista Gestão e Secretariado, vol. 1, n. 2, 122-141.

Neves, M. H. M. (1997). A gramática funcional. São Paulo: Martins Fontes.

Ortega, C. C., Araujo, L. F. (2011). Secretária Executiva: estresse e emoção no trabalho. Revista Gestão e Secretariado, vol.2, n.1, 131-157.

Sabino, R. F. \& Andrade Júnior, J. A. F. (2011). Secretariado: formação e mercado no estado de Sergipe. Revista Gestão e Secretariado, vol. 2, n.1, 6-31.

Sanctis, R. J. O. \& Abib, I. V. (2010). Ensino de língua estrangeira no curso de secretariado executivo bilíngua: buscando um caminho para as análises de necessidades específicas. Revista Gestão e Secretariado, vol. 1, n.1 186-198.

Sartori, T. (2011). Comportamento organizacional: um estudo de satisfação de secretários executivos no estado do RS. Revista Gestão e Secretariado, vol. 2, n.1, 32-55.

Scott, M. (2009). WordSmith tools. Oxford University Press.

Silva, D. A. O. \& Polaczek, M. (2010). Questões terminológicas em línguas estrangeiras e suas implicações para o profissional da área de secretariado. Revista Gestão e Secretariado, vol. 1, n. 2, 77-92.

Swales, J. (1990) Genre analysis: English in academic and research settings. Cambridge: Cambridge University Press.

Swales, J. M.; Feak, C. B. (1999) Academic writing for graduate students. Michigan: The University of Michigan Press.

Vitalis, L. W.; Geötzke, L. D \& Andriolo, L. J. (2011). Da simples arquivística à modernidade digital. Revista Gestão e Secretariado, vol. 2, n.1, 56-76.

Whitaker, M. C. \& Cavalcanti. T. N. (2010). Ética e sigilo na empresa e os profissionais de secretariado. Revista Gestão e Secretariado, vol. 1, n.1, 25-45.

Zanon, M. (2010). Os manuais de correspondências comerciais (1950-2000): uma interpretação à luz da historiografia linguística. Revista Gestão e Secretariado, vol. 1, n.1, 139-163. 